\title{
Erratum to: Thermal Evolution of Three Selected Preceramic POSSs Into Ceramic Materials
}

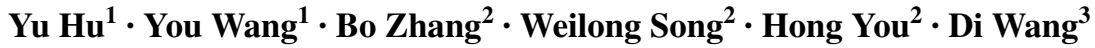

Published online: 6 July 2017

(C) Springer Science+Business Media, LLC 2017

\section{Erratum to: J Inorg Organomet Polym \\ DOI 10.1007/s10904-017-0580-2}

The original version of this article unfortunately contained a mistake. The curves in Fig. 4a were missing. The correct version of Fig. 4 is given below. The original article was corrected.

The online version of the original article can be found under doi:10.1007/s10904-017-0580-2.

$\mathrm{Yu} \mathrm{Hu}$

huyu80@hit.edu.cn

$\bowtie$ You Wang

y-wang@hit.edu.cn

Bo Zhang

1018548187@qq.com

Weilong Song

174545494@qq.com

Hong You

youhong@ hit.edu.cn

Di Wang

diwang1030@126.com

1 School of Materials Science and Engineering, Harbin Institute of Technology, Harbin 150001, China

2 State Key Laboratory of Urban Water Resource and Environment, Harbin Institute of Technology, Harbin 150001, China

3 School of Materials Science and Engineering, Northeast Forestry University, Harbin 150040, China 




Fig. 4 TG-DTA curves for transformations of the POSSs at the pyrolysis temperature. a OTMAP, b DPP, c OMP 